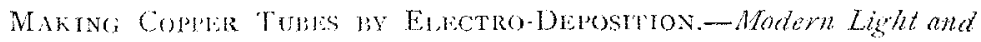
Heat, 4, 324, gives us the follewing description of an interesting method of obtaining copper tubes by an electrolytic process, which has recently been devised by Mr. W. Elmore, of Encrland. By this method tubes having a tensile strength of from fifty to roo per cent. in excess of brazed lubes are easily made. The process is very simple and consists in depositing the copper on an iron cylinder which is constantly revolving in the bath at a fixed rate of speed. An agrate burnisher, which moves slowly from end to end of the cylinder, much on the plan of the tool of a screw-cutting lathe, rubs down the fine crystals of copper, matting them together. When the deposit is sufficiently thick the cylinder is taken from the bath and subjected to the temperature of superheated stcam, when the sudden expansion of the copper tube frees it from the iron core, and it can be removed. The breaking strength of such tubes is said to be from twenty-seven to forty-one tons per square inch.

W.

A Demicate Thest for Bismutis. E. B. Stone (Jour. Soc. Chen. IndusIry, $\left(\mathbf{6}, 4 I^{6}\right)$. - When a dilute solution of bismuth sulphate, containing but little free sulphuric acid, is treated with a few drops of concentrated potassium iodide solution, a beautiful yellow color is produced, and is sensible with 0.00001 gramme bismuth oxide in ten cubic centimetres of solution. On account of the uncertainty which follows the similarity of the color to that which would be produced by the separation of a little iodine, Dr. Watson proposes that a little solution of lead nitrate be added to the neutral or only faintly acid liquid before adding the potassium iodide. The mixture of precipitated lead and bismuth iodides then has a color varying from orange to deep red. By careful operation, less than a miliionth of bismuth in solution may thus be detected.

W. H. G.

\title{
ENGINEERING.
}

Digist of a Report on Current Meter Observations, Mississippi River, near Burlington, Ia., I 879, by G. A. Marr. (Prepared by G. L. Martin, Department of (ivil Engineering, University of Pennsylvania).

In I878, Major F. U. Farquhar, U. S. E., was instructed to examine the Mississippi River above the mouth of the Illinois, for the purpose of forming a plan for the improvement of the low water navigation of this river and that of the Missouri. The portion of the river specially selected for study was between Burlington and Montrose. At the same time and place, a serics of observations with current meters, with a specially constructed chronograph, was undertaken. The work was inaugurated by Major Farquhar, with Capt. B. D. Greene, U.S. E., in charge of the field observations for a portion of the time, but Mr. G. A. Marr, Assistant Engineer, "who submits the final report, was in immediate charge of the field work, and has prepared the tables and plates showing the results."

The apparatus used consisted of seven current meters and a chronograph, which was constructed under the direction of Major Farquhar. The chronograph was provided with eight pens working independently, so that six could 
be used for current meters, giving an independent and complete record for each, while at the same time the two outside pens could be connected in one circuit for a time record by "being connected with a break circuit chrono. meter, and marking intervals of one second on each edge of the sheet." Instead of using a single meter and lowering it to different depths, six meters were used simultancously as "on account of the great fluctuations in velocity, not only from the surface downward, but also in the whole volume of the water, it appeared that a system which would give simultaneous observations at several distinct points in a vertical plane would give much more reliable and valuable information than the use of a single meter at different depths."

For determining the current velocities, the current meters were held in "position at their various depths by a wire rope," the foot of which was held by a mushroom anchor weighing 150 pounds. The six meters used for the observations were placed at equal intervals from the surface to the bottom of the river.

R.ATING THE METERS.

The meters were frequently tested, and for this purpose a frame was prepared, which was held in a horizontal position and at right angles to the direction of the current. The meters were placed in the frame and carefully set at the same height. This gave a comparison of the meters at the same depth, and to eliminate errors due to lateral variations in the current, the meters were reversed on the frame. Arrangements were also made for comparing the velocities as determined by meters and by floats. In the greater number of the observations, the floats were tied at mid-depth. From a study of the results, it was found that the velocity was not uniform over different sections, and hence a comparison of the velocity of the float with that of the meter located just below the section could not be expected to give definite results.

From the chronographic sheets, which give a record for the whole six meters, the velocities for each minute is given and the curve plotted graphically. The depths and the observed velocities at these depths are taken as the co-ordinates and the curve drawn, from which the velocity at any point may be scaled. The mean average velocity of the water at the different depths of the same section of the river is obtained by averaging the mean vertical velocity curves for the different minutes. Thus, on October 7 th, at the section having a depth of $19^{\circ} 5$ feet, nineteen different minute velocities are obtained for each meter. The final curve is drawn from the means of these.

RATIO OF MID-DLPTH TO MEAN VELOCITY.

The special object in view in obtaining these results was to find the ratio between the velocity at mid-depth and the mean velocity. To do this, the velacity at mid-depth was taken from the plotted curve. The mean velocity was obtained from averaging the velocities at a large number of depths. For this purpose the results are taken from the mean vertical velocity curve for each $0^{\prime} 4$ of a foot in depth. Humphreys and Abbot's formula, giving the ratio of mid-depth to mean velocity, is as follows:

$$
V_{\mathbf{m}}=V_{\frac{1}{2}} d-\frac{1}{12}(b v)^{\frac{1}{2}}
$$


in which

$$
b=\frac{160}{(\nu+1 \cdot 5)^{\frac{1}{2}}}
$$

and $V_{\text {xi }}$ is the mean velocity, $V_{\frac{1}{2}} d$ is the mid-depth velocity, $D$ is the depth and " $v$ the mean velocity of the whole cross section of the river." We now see what time and labor would be saved if a number could be determined which would express the ratio. In the equation, " $v$ " is needed and it is difficult to obtain. In the present case it was found from "the mean velocities as determined on cross section I." These velocities were plotted and "from the plot the value of $v$ could be taken very closely for any stage." The gaugings referred to were taken at the same time as the current meter observations. Thus, it is seen, the same opportunity for error offers itself in this case as in the other. The difference can be seen from an inspection of the annexed table, which is a small portion of one of the most important ones given in the report. To it has been added a column for the same day, so that a comparison might be made of the results derived from Humphreys and Abbot's formula and those obtained by using the coefficient. In both cases the mid-depth velocity used is the same, being that obtained from the current observations. There have also been added two columns not in the report. The first is the mean velocity taken from the plates for the depths corresponding to 6 of the total depth, and the second shows the difference between the mean velocity and that obtained by taking -6 of the depth.

INVESTIGATION AS TO RELATTVE ACCURACY OF DETERMINIAG MEAN VELOCITY BY A SINGLE OBSERVATION AT PROPER DEPTHS.

For obtaining the ratio of mean to mid-depth velocity, twenty-five results were obtained from the observations, giving a mean coefficient of 958 with a probable error of 029 . If it were possible to obtain a ratio of the depth of mean velocity to the whole depth with but a slight probable error, it would againgreatly simplify the work. From the present investigations, the probable error for the latter is greater than for the former, being $07 \mathrm{r}$, the ratio of $\frac{D_{\mathrm{m}}}{D}$, or of depth of mean velocity to total depth is 622 . Yet it might be possible to obtain sufficiently accurate results by taking the mean velocity as that found at a distance from the surface equal to 6 of the total depth. For this purpose the two additional columns have been prepared. From an inspection of the twenty-five results it is found that the coefficient 6 gives results in some cases closer to the true velocity than those given by 958 . The extremes are, for 6 , 075 and for 958 , 059 . It will be seen, therefore, that a sufficiently accurate result for most purposes can be obtained by taking the mean velocity as that given by the meter when placed at a depth from the surface equal to 6 of the total depth.

For the purpose of giving some definite knowledge concerning the question of velocities, the experiments were worthy of the trouble which Mr. Marr took to obtain the statements, but it is hardly possible to undertake such careful observations in every case. The circumstances and phenomena connected with the matter are so variable that the results can never be obtained with the desired degree of accuracy at any one point. 


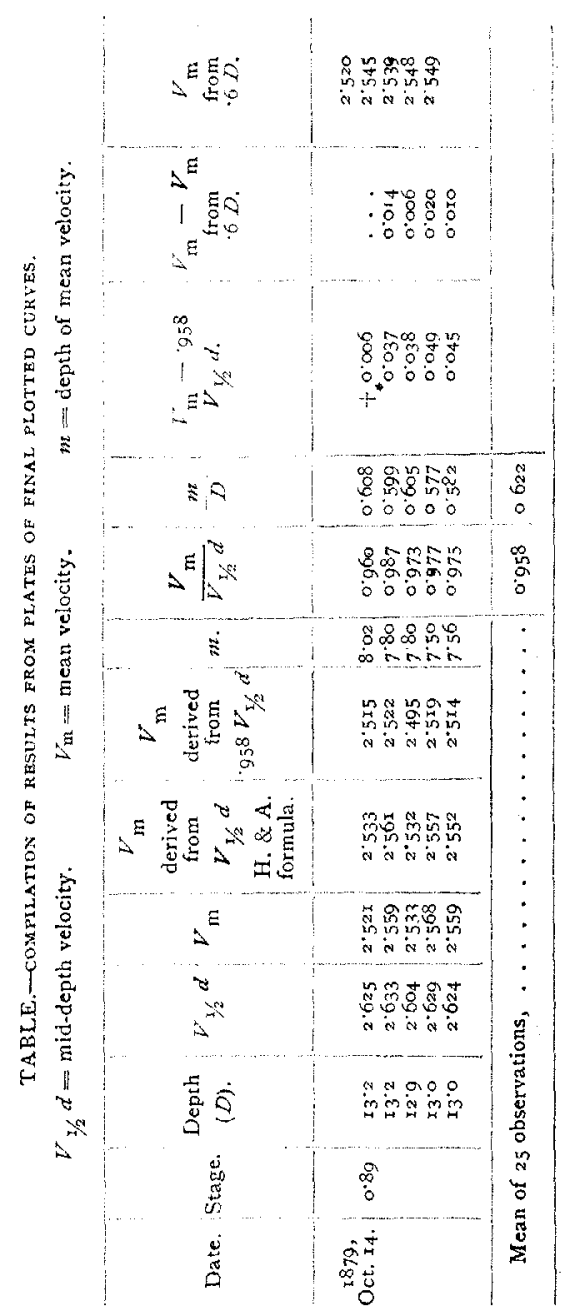

L. M. H.

The Simonds Rolling Machine.-Fitchburg, Mass. (Boston Herald of Friday, February 24, 1888.) This unique machine is said by mechanical experts to be "the grandest mechanical invention of the age," marking a " new era in the manufacture of iron and steel." It is briefly described as a machine in which two flat surfaces, acting vertically or horizontally, and moving in opposite directions, with adjustable dies fixed on them, roll in one motion a piece of metal of regular or irregular shape, and in almost any pattern desired.

The work is perfectly accurate and very rapidly done. It is as if one took a red-hot steel bar and inserted one end of it in the machine and by 
one stroke obtaincd the desired form, say a perfect sphere, or a conical shot, a chain screw or a bolt with thread, head and all complete, a caraxle or a tiny calk for lumbermen's shoes; spindles or taper pins. For a vast number of articles it supersedes the work of the lathe, trip-hanmer, planer and other machines requiring much loss of time and waste of material, for instead of cutting it away, it produces the proper form and size by com. pression and thus increases the strength of the prodiuct.

The invention is the outcome of a discussion upon a method of manufacturing a bolt, in which Mr. Geo. F. Simonds used, for illustration, a pencil rolled between the palnus of the hand, and this was the grerm which has been developed into the wonderful machine now running at the Simonds Brothers \& Co's works at Fitchburg, Mass. L, M. H.

\section{Franklin Institute.}

[Proceedings of the Stated Meeting; held Wednesday, March 27, I888.]

Hall of the Institute, Philadelphia, March 21, 1888.

Vice-President, W. P. TAтHAM, in the Chair.

Present, I 32 members and fifty-two visitors.

Accessions to membership since last meeting, two.

Mr. FRED. E. IvEs read a description of his suggestions for taking color photographs, and cxhibited a specimen picture with the lantern.

Mr. A. O. Grancier gave an oral description of the incandescent gas burner, adapted for non-luminous gas of any description, invented by Auer $v$. Welsbach, and exhibited a number of the burners in operation.

Mr. Morkis P. JANNEY, of Easton, described and exhibited the operation of an automatic "Electric Water-Level Indicator" for steam boilers.

The above communications have been referred for publication.

Dr. WM. H. Grezene exhibited and described (for Messrs. Jas. W. Queen \& Co., Agts.) some improved forms of fine balances.

The Secretary's report embraced the description and exhibition of a selfwinding clock, on behalf of Messrs. Breitinger \& Kunz, of Philadelphia, and of a number of specimens of the new product called Vulcabeston, made by the Johns-Pratt Company, of Hartford, Conn.

The presiding officer announced in suitable terms the death of Prof. JAs. C. Booth, for many years an active member of the INSTITUTE and of its staff of instructors.

Mr. S. LLOVD WIEGAND followed with a eulogy of the deceased, in which he specially referred to his admirable qualities as a teacher. He moved that a committee be appointed to prepare an appropriate memorial for publication. The motion was carried.

The President appointed Messrs. S. Lloyd Wiegand (Chairman), Chas. M. Cresson, M. D., and Alex. E. Outerbridge, Jr., as the Committee.

Adjourned.

WM. H. WaHL, Secretary. 